\title{
ESTILOS DE ADMINISTRAÇÃO DO CONFLITO ENTRE ENFERMEIROS(AS): Validação de instrumento 1
}

STYLES OF CONFLICT ADMINISTRATION AMONG NURSES: INSTRUMENT UALIDATION.

\author{
Márcio Tadeu Ribeiro Francisco ${ }^{2}$ \\ Araci Carmen $\mathrm{Clos}^{3}$ \\ Iraci dos Santos ${ }^{4}$ \\ Eliel de Oliveira Larrubia ${ }^{5}$
}

RESUMO: O presente estudo teve por objeto as modalidades de administração de conflito adotado por enfermeiros na prática profissional. Considerando a Teoria do "Grid" Gerencial (BLAKE \& MOUTON, 1997), o conflito pode ser resolvido em diferentes níveis de qualidade ou não ser solucionado, influenciado pelo estilo de comportamento gerencial. Objetivou-se identificar os estilos de administração dos conflitos adotados por enfermeiros, analisando suas interaçōes. Foi testado um questionário com 25 itens, composto em sua maioria por adágios populares que expressam os cincos modelos básicos de estilos gerenciais. A pesquisa ocorreu no Hospital Universitário Pedro Ernesto da Universidade do Estado do Rio de Janeiro, no período de junho de 1996 a agosto de 1997, tendo sido aplicados o método descritivo e a técnica de análise de função através de "check-list". A análise fatorial dos itens demonstrou a ocorrência de oito fatores interdependentes, delineando os seguintes estilos adotados por enfermeiros: confrontação, negociação, enfrentamento, conciliação, manipulação, aceitação, submissão e retirada. Os autores recomendam a revalidação do instrumento de coleta de dados.

UNITERMOS: Gerência - Relacionamento interpessoal - Liderança em enfermagem.

ABSTRACT: The present study has as an object the modalities of conflict administration adopted by nurses in professional praxis. Considering the Management Grid Theory (BLAKE \& MOUNTON, 1978), the conflict can be solved in different levels of quality or even, not solved, influenced by the manager behavior model. It is intended to identify nurses managering styles in conflict administration, analyzing their interactions. A questionnaire composed with 25 items, in its majority of popular adagios which express the five basic models of the Management Grid, has been tested. The research was run at the Rio de Janeiro State University Pedro Ernesto University Hospital from June, 1996 to August, 1997, and descriptive method and check-list schedule type functional analysis technique have been used. The factorial analysis of items has showed an occurrence of eight interdependent factors which designing the following styles that have been adopted by nurses: confrontation, negotiation, facing, conciliation, manipulation, acceptance, submission and withdrawing. The authors recommend data collect instrument revalidation.

KEYWORDS: Management - Interpersonal relation - Leadership in nursing.

${ }^{1}$ Trabalho apresentado no $49^{\circ}$ CBEn. - Belo Horizonte - MG, dezembro de 1997.

2 Professor Adjunto da Faculdade de Enfermagem/UERJ - Coordenador de Campi Regionais IUERJ.

${ }^{3}$ Professora Assistente da Faculdade de Enfermagem/UERJ - Assessora da Coordenadoria de Campi Regionais/UERJ.

${ }^{4}$ Professora Titular de Pesquisa em Enfermagem - Faculdade de Enfermagem/UERJ.

${ }^{5}$ Professor do Departamento de Enfermagem Médico-Cirúrgica da Faculdade de Enfermagem da UERJ - Diretor da Coordenadoria de Enfermagem do Hospital Universitário Pedro Ernesto. 


\section{INTRODUÇÃO}

Diversos autores têm estudado como as pessoas se comportam diante de situações de conflito, classificando-as nos chamados "estilo de administração do conflito". Tais estilos têm sido identificados como categorias mutuamente excludentes, porém não se tem delineada uma explicação teórica ou uma comprovação empirica sobre a interdependência que existe entre os mesmos, devido à complexidade do comportamento humano.

Diante do exposto, a presente investigação tem por objetivo geral constatar o tipo de interdependência que se pode atribuir aos estilos de administracão do conflito adotados por enfermeiros(as). Pretende-se, também, neste trabalho, o alcance dos objetivos específicos:

- Identificar os "estilos de administração de conflito" adotados por enfermeiros(as) na prática profissional.

- Determinar a interdependência que existe entre os diferentes "estilos" identificados, explicitando os seus significados.

O estudo desenvolve-se com apoio em pressupostos da teoria do "Grid" Gerencial (Blake \& Mouton, 1997), limitando-se aos aspectos relativos ao conflito.

\section{MARCO TEÓRICO}

A teoria do "Grid" Gerencial (BLAKE \& MOUTON, 1997) prevê cinco estilos básicos de conduta na administração do conflito: "confrontação", "conciliação", "facilitação", "repressão" e "retirada". Os outores citados apresentam os seguintes exemplos de manifestação dessas atitudes frente ao conflito:

- Estilo 1.1 - Retirada: demorar na resposta, esquecer-se do problema, deixar que o tempo resolva as questões das respostas que não impliquem em compromisso com o problema. Sua solução é evitar o conflito.

- Estilo 1.9 - Facilitação : desenvolve ações que mantenham a harmonia entre as partes, incapacidade de usar métodos diretos com ações fortes, apelar para sentimentos e razões para insegurança. Sua solução: tenta ser razoável com ambas as partes e depois passa para a reconciliação através do apaziguamento.

- Estilo 9.1 - Repressão: comportamento que denota o clima de luta aberta, apresenta argumentos tipos "ganha-perde", refere-se a desacordos ilógicos. A solução do conflito reside na autoridade. O conflito mina a estrutura do poder/autoridade; o conflito deve ser controlado antes que se torne incontornável. 
- Estilo 5.5 - Conciliação: estabelece previamente as regras do jogo para legitimar sua situação e divide as diferenças entre as partes. A solução do conflito prevê que se deva tomar algo de ambas as partes para colocá-las juntas em situação que possam cada um obter algo.

- Estilo 9.9 - Confrontação: quando surgem desacordos sobre o que e como fazer, sustenta que as pessoas devem ser ouvidas e se deve garantir a sua expressão. A solução está na confrontação direta: assume que se deve adotar as ações necessárias e não se deve gastar energia e tempo com "rodeios" ao conflito.

A administração do conflito está determinada por duas variáveis: o interesse próprio e a relação entre as partes. $O$ interesse próprio refere-se àquilo que se quer conseguir ou manter e a relação é o grau da interdependência das partes, isto é, a necessidade de uma pessoa permanecer junto de outra.

$\mathrm{Na}$ "confrontação", predominam igualmente a relação e o interesse e a pessoa preocupa-se com ambos os aspectos com igual intensidade. Em contrapartida, a "repressão" é caracterizada pela preponderância do interesse sobre a relação e a "retirada" tende a ignorar ambas as variáveis - o interesse e a relação.

A interação do interesse e da relação, na "facilitação" e na "conciliação" , é mais complexa. A "facilitação" implica no predomínio da relação sobre interesse, o que leva a uma tendência à "retirada" quando o que está em jogo é o interesse. Sem dúvida, a preocupação pela relação pode ser um meio para prevalecer seu próprio interesse. Assim, pode-se pensar na possibilidade da ocorrência de dois estilos diferentes: um com tendência à "retirada" e outro aproximado à "repressão".

$\mathrm{Na}$ conciliação, a pessoa parece estar disposta a ceder parte de seu interesse para que a relação não se deteriore em sua totalidade ou a arriscar parte da relação para que seus interesses não se percam completamente. Neste caso, também é preciso pensar na possibilidade da ocorrência de dois estilos: aproximados da "retirada" ou da "pressão", mas com matizes distintas das delineadas na "facilitação".

\section{METODOLOGIA}

Aplicou-se o método descritivo e a técnica de análise de função, através da utilização de "Check-list", para o estudo dos estilos de administração do conflito adotados por enfermeiros(as).

A pesquisa foi realizada no Hospital Universitário Pedro Ernesto da Universidade do Estado do Rio de Janeiro, no período de julho de 1996 a agosto de 1997. 
Por tratar-se de validação de instrumento, a amostra intencional limitou-se a 50 enfermeiros(as) que se dispuseram a participar deste trabalho. Foram investigados os seguintes atributos pessoais dos(as) enfermeiros(as): sexo, faixa etária e estado civil. Entre as características empregatícias pesquisadas, selecionou-se o tempo de exercício profissional para análise neste trabalho.

A distribuição das pessoas por sexo relaciona 46 do sexo feminino e quatro homens. Quanto à faixa etária, estas foram agrupadas em quatro classes, tendo como limite inferior a classe de 25 a 29 anos e como limite superior o grupo de 40 a 44 anos de idade. Houve predominâncias - 18 - da classe mais jovem (de 25 a 29 anos), entre o quais 16 são mulheres. Seguem em ordem decrescente, 14 enfermeiros(as) situados(as) na faixa imediata de 30 a 34 anos, destacandose 13 mulheres, (Ver Tabela 1).

\section{TABELA 1 - DISTRIBUIÇÃO DOS(DAS) ENFERMEIROS(AS) POR SEXO E FAIXA ETÁRIA \\ HUPE / UERJ - JUNHO/1996 A JULHO/1997}

\begin{tabular}{c|c|c|c}
\hline \multirow{2}{*}{ FAIXA ETÁRIA } & \multicolumn{2}{|c|}{ SEXO } & TOTAL \\
\cline { 2 - 4 } & MASC. & FEM. & Fi \\
\hline $25-29$ & 2 & 16 & 18 \\
\hline $30-34$ & 1 & 13 & 14 \\
\hline $35-39$ & 1 & 10 & 11 \\
\hline $40-44$ & - & 07 & 07 \\
\hline TOTAL & $\mathbf{4}$ & $\mathbf{4 6}$ & $\mathbf{5 0}$ \\
\hline
\end{tabular}

Na distribuição da amostra por estado civil e sexo, predominam - 23 - os(as) solteiros(as), entre os quais 21 são do sexo feminino. Seguem, em ordem decrescente de freqüência: 16 casados(as), dos quais apenas um é do sexo masculino, quatro separados (sendo três mulheres), seis mulheres desquitadas/divorciadas e apenas uma viúva (Ver Tabela 2).

TABELA 2 - DISTRIBUIÇÃO DOS ENFERMEIROS POR SEXO E ESTADO CIVIL

\begin{tabular}{l|c|c|c}
\hline \multirow{2}{*}{ ESTADO CIVIL } & \multicolumn{2}{|c|}{ SEXO } & TOTAL \\
\cline { 2 - 4 } & MASC. & FEM. & Fi \\
\hline Solteiro & 2 & 21 & 23 \\
\hline Casado & 1 & 15 & 16 \\
\hline Separado & 1 & 03 & 04 \\
\hline Desquitado/Divorciado & - & 06 & 06 \\
\hline Viúvo & - & 01 & 01 \\
\hline \multicolumn{1}{c|}{ Total } & 4 & $\mathbf{4 6}$ & $\mathbf{5 0}$ \\
\hline
\end{tabular}


Relacionando o tempo do exercício profissional por sexo, a distribuição dos sujeitos indica a predominância - 23 - dos que exercem a profissão há menos tempo (de 2 a 5 anos),entre os quais 21 são do sexo feminino. Seguem, em ordem decrescente de freqüência, 19 enfermeiros que trabalham há pelo menos 6 anos e, no máximo, há 9 anos; destes, 18 são mulheres. Apenas oito sujeitos estão atuando na enfermagem há mais de 9 anos e no máximo há 18 anos, (Ver Tabela 3).

\section{TABELA 3 - DISTRIBUIÇÃO DOS ENFERMEIROS POR SEXO E TEMPO DE EXERCÍCIO PROFISSIONAL}

\begin{tabular}{c|c|c|c}
\hline \multirow{2}{*}{$\begin{array}{c}\text { TEMPO DE EXERCÍCIO } \\
\begin{array}{c}\text { PROFISSIONAL } \\
\text { (em anos) }\end{array}\end{array}$} & \multicolumn{2}{|c|}{ SEXO } & TOTAL \\
\cline { 2 - 4 } & MASC. & FEM. & Fi \\
\hline $2-5$ & 2 & 21 & 23 \\
\hline $6-9$ & 1 & 18 & 19 \\
\hline$>9^{*}$ & 1 & 07 & 08 \\
\hline TOTAL & $\mathbf{4}$ & $\mathbf{4 6}$ & $\mathbf{5 0}$ \\
\hline
\end{tabular}

*Encontrou-se o máximo de 18 anos em exercício profissional

No tratamento dos dados, utilizou-se o "kit" SPSS (NIE et alii, 1985), aplicando-se a "análise fatorial de componentes principais". Posteriormente, foi realizada uma "rotação oblíqua", que, na prática, permite a manipulação adequada dos dados em função dos objetivos. A confiabilidade da escala é estabelecida pelo método de consistência interna, ou seja, a correlação do item com o total da escala, a partir do coeficiente 0,35 . Assim, a escala inicial com 33 itens foi reduzida para 25 (Ver modelo em anexo). Para aceitar um item como integrante do fator, estabeleceu-se um coeficiente fatorial mínimo de 0,35 . Os estilos gerenciais "Grid" foram representados pelos respectivos itens, conforme o crivo de respostas a seguir:

Crivo de respostas para identificação dos estilos de administração do conflito

\begin{tabular}{|c|l|}
\hline ESTILOS & \multicolumn{1}{|c|}{ NÚMERO DOS ITENS } \\
\hline $9.9-$ Confrontação & $4,8,12$ e 24 \\
\hline $5.5-$ Conciliação & $1,7,9,11$ e 19 \\
\hline $9.1-$ Repressão & $10,14,16$ e 21 \\
\hline $1.9-$ Facilitação & $2,5,6,13,15,17,20,23$ e 25 \\
\hline $1.1-$ Retirada & 3,18 e 22 \\
\hline
\end{tabular}




\section{Instrumentação}

A escala foi desenvolvida pelos autores desta pesquisa em 1996 e tem por finalidade identificar os estilos de administração do conflito adotados por gerentes, que neste trabalho são representados por enfermeiros(as). Os 25 itens da escala - em sua maioria adágios populares - expressam os modelos de condutas gerenciais do conflito conforme descrição de Blake E Mouton (1997), que são: confrontação (ideal), conciliação, repressão, facilitação e retirada.

Visando avaliar a adequação da escala à finalidade da pesquisa, a mesma foi submetida à apreciação de oito juizes, especialistas em validação de instrumentos para pesquisa, os quais aprovaram todos os adágios propostos, com sugestão de alteração de apenas três vocábulos que foram aceitos nesta validação. Posteriormente, o instrumento foi aplicado em 10 enfermeiros, com o objetivo de verificar sua adequação à população alvo. A análise dos dados obtidos indicou a pertinência dos itens na escala, não tendo havido necessidade de modificações. Finalmente, o questionário foi respondido por 50 enfermeiros que concordaram em contribuir em sua validação.

O instrumento de coleta de dados, além da escala, apresentava quatro questões com respostas abertas para caracterização dos sujeitos, ou seja: idade, sexo, estado civil e tempo de exercício profissional. Ao responderem à escala, coube aos sujeitos optar pelos itens que melhor expressassem a sua maneira de gerência em enfermagem. Procedeu-se à coleta de dados no período de junho de 1996 a julho de 1997, tendo sido os enfermeiros abordados individualmente em seu local de trabalho. Os questionários foram distribuídos no início do expediente e recolhidos ao seu término.

\section{Variáveis e tratamento de dados}

Foram selecionadas, como variáveis dependentes, as variáveis demográficas sexo, idade e estado civil e a variável empregatícia tempo de exercício profissional. À categoria profissional enfermeiro atribuiu-se a função variável independente.

\section{RESULTADOS E DISCUSSÃO}

A análise dos dados obtidos na amostra apontou 99 interações e oito fatores que surgiram como explicação de $100 \%$ da variança. A Tabela 4 mostra a percentagem de variança que cada fator representa e respectiva percentagem acumulada na análise dos itens do questionários aplicado. 
TABELA 4 - PERCENTAGEM DE VARIANÇA QUE CADA FATOR REPRESENTA E RESPECTIVA PERCENTAGEM ACUMULADA NA ANÁLISE DOS ITENS.

\begin{tabular}{c|c|c}
\hline FATORES & \% REPRESENTANTE DE CADA FATOR & \% ACUMULADA \\
\hline I & 22.7 & 22.7 \\
\hline II & 17.0 & 39.7 \\
\hline III & 14.3 & 54.1 \\
\hline IV & 13.1 & 67.1 \\
\hline $\mathrm{V}$ & 11.0 & 78.2 \\
\hline $\mathrm{VI}$ & 8.8 & 87.0 \\
\hline $\mathrm{VII}$ & 7.2 & 94.2 \\
\hline $\mathrm{VIII}$ & 8.8 & 100.0 \\
\hline
\end{tabular}

Considerando o critério estabelecido para a aceitação de um item como integrantes de um fator - um coeficiente fatorial mínimo de 0,35 , foram identificados oito fatores, os quais são descritos na TABELA 5.

\section{TABELA 5 - DISTRIBUIÇÃO DOS ITENS ACEITOS NO QUESTIONÁRIOS DEFINITIVO POR CORRELAÇÕES E FATORES ENCONTRADOS}

\begin{tabular}{|c|c|c|c|}
\hline FATORES & ORDEM & ITENS & VALOR FATORIAL \\
\hline \multirow{7}{*}{ I } & 1 & $\begin{array}{l}\text { Cavando e cavando descobre-se a } \\
\text { verdade }\end{array}$ & 0.854 \\
\hline & 2 & $\begin{array}{l}\text { Se não podes conseguir que } \\
\text { alguém pense como tu, faça com } \\
\text { que ele aja como desejas }\end{array}$ & 0.665 \\
\hline & 3 & $\begin{array}{l}\text { Uma negociação limpa não } \\
\text { acarreta disputas }\end{array}$ & 0.900 \\
\hline & 4 & Tome lá, dê cá: é jogo limpo & 0.452 \\
\hline & 5 & $\begin{array}{l}\text { Busque até encontrares e teu } \\
\text { trabalho não terá sido em vão }\end{array}$ & 0.357 \\
\hline & 6 & $\begin{array}{l}\text { Em uma discussão, perde menos } \\
\text { o que menos fala }\end{array}$ & 0.516 \\
\hline & 7 & Não removas um ninho de vespas & 0.626 \\
\hline \multirow{6}{*}{ II } & 1 & $\begin{array}{l}\text { Mais vale um pássaro na mão do } \\
\text { que dois voando }\end{array}$ & 0.878 \\
\hline & 2 & $\begin{array}{l}\text { Uma decisão acertada apoia-se } \\
\text { não apenas em fatos mas também } \\
\text { no conhecimento }\end{array}$ & 0.413 \\
\hline & 3 & $\begin{array}{l}\text { Quando alguém te acertar com } \\
\text { uma pedra, atinja-o com algodão }\end{array}$ & 0.398 \\
\hline & 4 & $\begin{array}{l}\text { Se não podes conseguir que } \\
\text { alguém pense como tu, faça com } \\
\text { que ele aja como desejas }\end{array}$ & 0.355 \\
\hline & 5 & $\begin{array}{l}\text { Aquele que luta e depois foge vive } \\
\text { para sua fuga }\end{array}$ & 0.928 \\
\hline & 6 & Tome lá, dê cá: é jogo limpo & 0.443 \\
\hline
\end{tabular}




\begin{tabular}{|c|c|c|c|}
\hline FATORES & ORDEM & ITENS & VALOR FATORIAL \\
\hline \multirow{7}{*}{ III } & 1 & $\begin{array}{l}\text { As palavras delicadas dobram } \\
\text { corações duros }\end{array}$ & 0.676 \\
\hline & 2 & $\begin{array}{l}\text { Aquele que não foge fará seu } \\
\text { inimigo fugir }\end{array}$ & 0.735 \\
\hline & 3 & $\begin{array}{l}\text { Se não podes conseguir que } \\
\text { alguém pense como tu faça com } \\
\text { que ele aja como desejas }\end{array}$ & 0.468 \\
\hline & 4 & $\begin{array}{l}\text { Busque até encontrares e teu } \\
\text { trabalho não terá sido em vão }\end{array}$ & 0.412 \\
\hline & 5 & $\begin{array}{l}\text { Em uma discussão, perde menos } \\
\text { o que menos fala }\end{array}$ & 0.372 \\
\hline & 6 & Elimine teus inimigos com cortesia & 0.618 \\
\hline & 7 & $\begin{array}{l}\text { Trocas de mimos fazem boas } \\
\text { amizades }\end{array}$ & 0.576 \\
\hline \multirow{7}{*}{ IV } & 1 & Olho por olho, dente por dente & 0.360 \\
\hline & 2 & $\begin{array}{l}\text { Uma decisão acertada apoia-se } \\
\text { não apenas em fatos mas também } \\
\text { no conhecimento }\end{array}$ & 0.513 \\
\hline & 3 & $\begin{array}{l}\text { Se não podes conseguir que } \\
\text { alguém pense como tu, faça com } \\
\text { que ele aja como desejas }\end{array}$ & 0.527 \\
\hline & 4 & A força sempre leva à razão & 0.942 \\
\hline & 5 & Tome lá, dê cá: é jogo limpo & 0.429 \\
\hline & 6 & $\begin{array}{l}\text { As boas palavras não custam } \\
\text { dinheiro }\end{array}$ & 0.965 \\
\hline & 7 & Não removas um ninho de vespas & 0.534 \\
\hline \multirow{6}{*}{ V } & 1 & Olho por olho, dente por dente & 0.634 \\
\hline & 2 & $\begin{array}{l}\text { Os argumentos do mais forte } \\
\text { sempre têm mais peso }\end{array}$ & 0.665 \\
\hline & 3 & A força sempre leva à razão & 0.353 \\
\hline & 4 & \begin{tabular}{|l|l|} 
Busque até encontrares e teu \\
trabalho não terá sido em vão
\end{tabular} & 0.714 \\
\hline & 5 & $\begin{array}{l}\text { Finque suas raizes onde queiras } \\
\text { ficar }\end{array}$ & 0.822 \\
\hline & 6 & $\begin{array}{l}\text { Trocas de mimos fazem boas } \\
\text { amizades }\end{array}$ & 0.502 \\
\hline
\end{tabular}




\begin{tabular}{|c|c|c|c|}
\hline FATORES & ORDEM & ITENS & VALOR FATORIAL \\
\hline \multirow{6}{*}{ VI } & 1 & $\begin{array}{l}\text { Aquele que não foge fará seu } \\
\text { inimigo fugir }\end{array}$ & 0.365 \\
\hline & 2 & $\begin{array}{l}\text { Venha e discutamos juntos, numa } \\
\text { boa relação }\end{array}$ & 0.618 \\
\hline & 3 & $\begin{array}{l}\text { Uma decisão acertada apoia-se } \\
\text { não apenas em fatos mas também } \\
\text { no conhecimento }\end{array}$ & 0.505 \\
\hline & 4 & $\begin{array}{l}\text { Quando alguém te acertar com } \\
\text { uma pedra, acerte-a com algodão }\end{array}$ & 0.557 \\
\hline & 5 & $\begin{array}{l}\text { As palavras agradáveis tornam } \\
\text { mais suaves os caminhos }\end{array}$ & 0.905 \\
\hline & 6 & $\begin{array}{l}\text { A paciência e a confiança movem } \\
\text { montanhas }\end{array}$ & 0.423 \\
\hline \multirow{5}{*}{ VII } & 1 & $\begin{array}{l}\text { É mais fácil conter-se do que } \\
\text { apartar-se da luta já começada }\end{array}$ & 0.808 \\
\hline & 2 & $\begin{array}{l}\text { Mais vale um pássaro na mão do } \\
\text { que dois voando }\end{array}$ & 0.387 \\
\hline & 3 & Tome lá, dê cá: é jogo limpo & 0.494 \\
\hline & 4 & $\begin{array}{l}\text { Em uma discussão, perde menos } \\
\text { o que menos fala }\end{array}$ & 0.403 \\
\hline & 5 & $\begin{array}{l}\text { Finque suas raizes onde queiras } \\
\text { ficar }\end{array}$ & 0.377 \\
\hline \multirow{3}{*}{ VIII } & 1 & $\begin{array}{l}\text { Quando dois discutem, o que cala } \\
\text { primeiro é o que merece louvor }\end{array}$ & 0.989 \\
\hline & 2 & Toma lá, dê cá: é jogo limpo & 0.357 \\
\hline & 3 & $\begin{array}{l}\text { A paciência e confiança movem } \\
\text { montanhas }\end{array}$ & 0.460 \\
\hline
\end{tabular}

Finalmente, foi estabelecida a correlação que os oito fatores guardam entre si, cujos resultados são apresentados na TABELA 6.

TABELA 6 - CORRELAÇÕES ENTRE OS OITO FATORES ENCONTRADOS NA ANÁLISE DOS ITENS DO QUESTIONÁRIOS

\begin{tabular}{c|c|c|c|c|c|c|c|c}
\hline FATOR & $\mathbf{1}$ & $\mathbf{2}$ & $\mathbf{3}$ & $\mathbf{4}$ & $\mathbf{5}$ & $\mathbf{6}$ & $\mathbf{7}$ & $\mathbf{8}$ \\
\hline 1 & 1.000 & 0.016 & 0.017 & 0.091 & 0.055 & 0.054 & 0.027 & 0.110 \\
\hline 2 & 0.016 & 1.000 & 0.029 & 0.085 & 0.045 & 0.079 & 0.189 & 0.119 \\
\hline 3 & 0.017 & 0.029 & 1.000 & 0.008 & 0.023 & 0.031 & 0.009 & 0.251 \\
\hline 4 & 0.091 & 0.085 & 0.008 & 1.000 & 0.057 & 0.094 & 0.093 & 0.012 \\
\hline 5 & 0.055 & 0.045 & 0.025 & 0.057 & 1.000 & 0.044 & 0.126 & 0.040 \\
\hline 6 & 0.054 & 0.079 & 0.031 & 0.094 & 0.044 & 1.000 & 0.022 & 0.047 \\
\hline 7 & 0.027 & 0.189 & 0.009 & 0.093 & 0.126 & 0.022 & 1.000 & 0.027 \\
\hline 8 & 0.110 & 0.119 & 0.251 & 0.012 & 0.040 & 0.047 & 0.027 & 1.000 \\
\hline
\end{tabular}


A interpretação dos fatores obtidos em relação aos itens analisados é resumida na discussão a seguir. Conforme Blake \& Mouton (1997), o estilo de administração de conflito denominado "confrontação" caracteriza-se pelos seguintes significados: a pessoa não foge diante de uma situação de conflito, busca e insiste em encontrar uma solução. Os dois pressupostos básicos que definem este estilo são: "Finque suas raízes onde queiras ficar" e "Busque até encontrares e teu trabalho não terá sido em vão". Rejeita o uso do poder e a pressão para alcançar vantagens e em algumas oportunidades pode oferecer negociações para chegar a um acordo.

Blake \& Mouton (1997) denominaram "negociação" a outro estilo de conduta, cujo fator assume que a resolução do conflito implica em negociação direta, pois parte do pressuposto de que "uma negociação limpa não acarreta disputa". Esta negociação pressupõe uma atitude de busca positiva de solução de conflito, a qual requer firmeza, de tal maneira que toda concessão resulte em retribuição. $E$, ao mesmo tempo, é entendido que deve haver certas concessões e andar com prudência para não ampliar ou reforçar o conflito: "Não removas um ninho de vespas".

O "enfrentamento" é outro estilo de conduta que se caracteriza por não fugir das situações de conflito, ao contrário, o sujeito se coloca face a face diante dele. Seu pressuposto básico é "Aquele que luta e depois foge vive para sua fuga". Sem dúvida, a tendência não é a de manter todo seu interesse senão de tratar de salvar algo definido. "Mais vale um pássaro na mão do que dois voando". Este estilo é manifestado por meio de comportamentos que "batem de frente" e conduzem à consecução dos próprios interesses.

O estilo "conciliação", segundo Blake \& Mouton (1997), manifesta a tendência de trocar algo em lugar de perder o todo, o qual se expressa no pressuposto básico de que "é mais fácil conter-se do que apartar-se da luta já começada". A pessoa trata de manter a defesa de seus interesses mas se inclina a ceder em parte para alcançar algo pretendido.

Para Blake \& Mouton (1997), a "manipulação" é estilo de conduta que se caracteriza por não querer abandonar a situação de conflito, mas buscando ganhar posições por meio das relações harmoniosas entre as partes. De fato, os dois pressupostos básicos são: "aquele que não foge fará seu inimigo fugir" e "palavras delicadas dobram corações duros". A ênfase na cortesia e nas boas relações tem por finalidade conseguir que a outra parte aceite um compromisso, o qual encobre o próprio interesse. 
A "aceitação" é o estilo que, diante do conflito, mostra uma preocupação fundamental pela conservação das boas relações interpessoais. O pressuposto fundamental é "as palavras agradáveis tornam mais suaves os caminhos". Ante as situações de conflito, preserva sempre a boa comunicação entre os envolvidos, atribuindo maior importância ao relacionamento entre as pessoas do que aos dados objetivos do conflito. Diante da agressão, responde com benevolência e suavidade, persistindo na defesa do relacionamento ainda que às custas de seus próprios interesses.

A "submissão" é o estilo de conduta que revela medo do poder (dos outros e do próprio). Seu pressuposto básico é a rejeição ao ditado "a força sempre leva à razão". Seu modelo de conduta está exemplificado no aforismo de que "as boas palavras não custam dinheiro". Rechaça soluções baseadas na pressão e prefere ceder em seu próprio interesse para conservar o relacionamento interpessoal.

De acordo com Blake \& Mouton (1997), a "retirada" é o estilo de conduta que não enfrenta o problema e prefere fugir ao conflito. Seu pressuposto é "quando dois discutem, o que cala primeiro é que merece mais louvor". Sem dúvida, não revela abertamente sua ação de "retirada", ela é disfarçada.

Por outro lado, pode ser observado que há interdependência entre "os estilos", confirmando-se, assim, o exposto no segundo objetivo desta pesquisa. A análise dos resultados indica que a "confrontação" continua caracterizando um estilo no qual igualmente predominam a "relação interpessoal" e o "interesse". Paralelamente a este estilo, aparece um adicional no qual o indivíduo parte do princípio de que há necessidade de fazer trocas justas na solução de conflito. A este estilo atribuímos a denominação "negociação".

Pode-se dizer que na "confrontação" a pessoa tende a perceber as situações mais como um conflito de "meios" do que um conflito de "interesses" e na "negociação" o sujeito está mais atento para a possibilidade de vislumbrar um conflito de interesse do que um conflito de "meios".

A "repressão" não se revelou como um estilo interdependente, fato que deve ser investigado em maior profundidade, antes de obter deduções conclusivas. De fato, é possivel que tenha sido mascarado, seja por falha do instrumento, pela amplitude da amostra ou por fatores culturais que estariam indicando uma ausência de afirmação na defesa do "interesse próprio" entre os enfermeiros estudados. Certamente, este estilo é encontrado no "enfrentamento", fator derivado da "conciliação" e na "manipulação", que se deriva da "facilitação". 
A "conciliação" aparece explicada por dois fatores: conciliação e enfrentamento. No primeiro, predomina o interesse pela relação interpessoal e no segundo, há preocupação maior pelo próprio interesse.

A "facilitação" foi decomposta em três fatores: "manipulação", "aceitação" e submissão". No primeiro, há predominância do interesse próprio em cujo benefício são manipuladas as relações interpessoais e, em contrapartida, nos segundo e terceiro fatores, a preocupação maior recai sobre as relações.

Finalmente, a "retirada" foi o estilo que permaneceu conforme a descrição inicial.

A análise de dados indicou não haver correlação entre os estilos encontrados e as variáveis sexo, idade, estado civil e tempo de exercício profissional.

\section{CONCLUSÃO E RECOMENDAÇÕES}

Em síntese, os estilos da administração do conflito adotados pelos enfermeiros investigados são: confrontação, negociação, enfrentamento, conciliação, manipulação, aceitação, submissão e retirada. São estilos interdependentes e não estão relacionados às variáveis sexo, idade, estado civil e tempo de exercício profissional.

É relevante o diagnóstico de condutas gerenciais desde que sua finalidade seja a definição de um ponto de partida para a melhoria dos desempenhos individual e de equipe visando a excelência assistencial, objeto da profissão enfermeiro.

O exercício da confrontação significa um desafio aos(às) enfermeiros(as) para um maior comprometimento consigo mesmo, com sua equipe e com seu trabalho, e estímulo para a criatividade e a excelência em suas realizações. Recomenda-se o aperfeiçoamento da escala e a replicação da pesquisa em amostra representativa, compromisso assumido pelos autores deste trabalho. 


\section{ANEXO - ESCALA PARA IDENTIFICAÇÃO DOS ESTILOS DE ADMINISTRAÇÃO DO CONFLITO}

No ORDEM

01

02

03

04

05

06

07

08

09

\section{ITENS}

Não removas um ninho de vespas

A força sempre leva à razão

Em uma discussão, perde menos o que menos fala

Cavando e cavando descobre-se a verdade

Elimine teus inimigos com cortesia

Venha e discutamos juntos, numa boa relação

Olho por olho, dente por dente

Finque suas raizes onde queiras ficar

Uma negociação limpa não acarreta disputas

Mais vale um pássaro na mão do que dois voando

Tome lá, dê cá: jogo limpo

Busque até encontrares e teu trabalho não terá sido em vão Quando alguém te acertar com uma pedra, atinja-o com algodão

Se não podes conseguir que alguém pense como tu, faça com que ele aja como desejas

Trocas de mimos fazem boas amizades

Aquele que não foge fará seu inimigo fugir

As palavras delicadas dobram corações duros

A paciência e a confiança movem montanhas

É mais fácil conter-se do que apartar-se da luta já começada

As boas palavras não custam dinheiro

Aquele que luta e depois foge vive para sua fuga

Quando dois discutem, o que cala primeiro é o que merece louvor

Os argumentos dos mais fortes têm mais peso

Uma decisão acertada apoia-se não apenas em fatos mas também no conhecimento

As palavras agradáveis tornam mais suaves o caminho 


\section{BIBLIOGRAFIA}

1. BLAKE, Robert; MOUTON, Jane. O Grid Gerencial. São Paulo: Pioneira, 1997.

2. NIE et alii. Statistics SPSS. New York: MKS, 1985.

3. SANTOS, Iraci; CLOS, Araci Carmen. A Pesquisa Quantitativa. In: GAUTHIER, Jacques et alii. Pesquisa em Enfermagem. Rio de Janeiro: Guanabara Koogan, 1997.

4. SANTOS, Iraci dos. Estilos gerenciais adotadospor enfermeiros na área de recuperação da saúde. In: GAUTHIER, Jacques e col. Pesquisa em Enfermagem. Rio de Janeiro: Guanabara Googan, 1997.

5. SANTOS, Iraci dos. A Sócio-Poética: um caminho para a pesquisa em enfermagem. R. Enferm. UERJ. RJ, v. 5. n. 1, p. 381-390, maio, 1997. 